\title{
The South African Young Spectroscopist Symposium: current model and future developments
}

Janette Cawood

Janette E. Cawood, "The South African Young Spectroscopist Symposium: current model and future developments," Proc. SPIE 9663, Eighth International Topical Meeting on Education and Training in Optics and Photonics, 96631C (6 October 2003); doi: 10.1117/12.2207496

SPIE Event: Eighth International Topical Meeting on Education and Training in Optics and Photonics, 2003, Tucson, Arizona, United States 


\title{
The South African young spectroscopist symposium: current model and future developments.
}

\author{
Janette E Cawood \\ President, South African Spectroscopic Society, PO Box 443, Saldanha, 7395. \\ jcawood@telkomsa.net
}

\begin{abstract}
The Young Spectroscopist Symposium is held annually for young scientists to present spectroscopic research projects. All ethnic groups are represented. Ratings are on merit alone without ethnic/gender considerations. The event is widely supported, with $80-85 \%$ attendance by previously disadvantaged population groups. Future developments are to extend support to young spectroscopists. (C)2003 Optical Society of America

OCIS codes: 300.6560Spectroscopy; 000.2060 Education
\end{abstract}

\section{Background}

Until 1997, the Young Spectroscopist Symposium (YSS) was held biennially at tertiary institutions in either Johannesburg or Pretoria. Academics who previously involved their students with the YSS were usually from a core group of South African Spectroscopic Society (SASS) members or colleagues in contact with these members. As a result of our national history, mainly the traditionally "white" scientific community supported the meetings, with the involvement of the traditionally "non-white" institutions being rare to non-existent.

In 1998, the newly elected Executive Committee took up the responsibility of being in charge of a very strong society with most of its founder members still actively contributing to the work it was doing. With successful predecessors such as emeritus professor James Willis, Dr Pat Butler, Dr Albert Strasheim and others, who had so much to give to the spectroscopic community in the past, it was essential that the society itself and the meaningful work it had done had to be continued. The society could not be allowed to slip into inactivity and a gradual loss of its members.

The Executive Committee aimed for the SASS to continue being of service to the new generation of spectroscopists, with enthusiasm in this science and the many fields of its application. The SASS had a proven track record for the advancement of knowledge and skill, which had to continue with new growth. Role models in the SASS were willing to support this ideal and help make it work.

The changes brought about as a result of our first democratic elections in 1994, meant that the SASS had to focus on bringing about change in the way we were operating. We were not naturally migrating fast enough across the racial boundaries that were a heritage from the past. Participation in our meetings and delegates attending our meetings were not a reflection of the country's scientific population. Integration was taking place, but at a very slow rate. As a result of this, certain aims became the focus of the Executive Committee to achieve during their term of office. They were to:

- Include activities that brought the younger generation of scientist in the country to our meetings.

- Bring the younger generation of different cultural backgrounds together to start liaisons between those with common interests.

- Help as many students as possible who had grown up in rural and poor urban areas and probably had limited exposure to science and technological developments prior to their studies.

- Stimulate communication and interaction amongst the developing chemists/geologists/physicists and others in the membership.

Success in these goals would co-incidentally also lead to the added benefits of growth and the continuation of the society.

\section{The current Young Spectroscopist Symposium "model"}

2.1 Meetings representing all spectroscopists

In the light of the background above, the obvious place to begin working was in the existing forum for younger scientists, the YSS. Our country's history made it difficult to arrange a scientific gathering with delegates of all our races attending and where the participants giving presentations were fully representative of our population. 
It was decided that the best approach would be to speak personally with representatives from tertiary institutions involved with spectroscopy education and research. Canvassing for support was required, especially at those tertiary institutions that were traditionally "non-white" education centres, such as the Vista University campuses of Soweto and Mamelodi near Pretoria. The traditionally "white" education centres were not really a problem as they were already participating to a degree, although not regularly enough for it to be sustainable without any prompting from the society. The best strategy for the traditionally "white" centers would be increased and focused advertisement of the YSS and the latter groups to get more involved.

During March 1999, a very colourful poster was prepared advertising the YSS to take place in August of that year. It took three full days to meet with six lecturers from different institutions, or various departments at these institutions, in the Gauteng region. The cooperation was wonderful to experience. Responses from individuals prepared to actively participate exceeded expectations.

As many copies of the advertisement of the YSS as could be afforded to be printed, were distributed at these meetings. The lecturers gave their full support by circulating the information amongst their post-graduates and putting the posters on their notice boards. Some of these very colorful notices were posted to the institutions farther afield.

Since then and to date, the YSS has had unreserved support from the lecturers in spectroscopy, not only in the Gauteng region, but also at a national level wherever spectroscopy is practiced. Other provinces involved are the Western Cape branch and to a lesser degree, the southern Natal branch of the SASS. As a result of this success, the YSS changed from a biannual to an annual event.

Over the years, a lot of effort has gone into getting spectroscopists from industry also involved. A few young spectroscopists from various industries have competed at the YSS. Participation from industry is hampered by the need for industrial secrecy - we could have more involvement from this sector if it were not for this factor. Industrial chemists attend the YSS as delegates/spectators in sufficient numbers for us to be assured that, not only are they supporting the event by taking the time to spend a day listening to the presentations of other developing spectroscopist, they are also benefiting in the knowledge of the type of research the academics are doing.

Approximately $80 \%$ of spectroscopy done in industry is located in the Gauteng province. This is the reason why the YSS is usually held at one of the universities or technikons in that region.

Following on the success of the symposia held at the two Vista University campuses, the event has been held the Pretoria Technikon, Technikon Witwatersrand, University of Pretoria and this year, at the Rand Afrikaans University. The YSS has become well known in academic circles and is supported by most lecturers in the field of spectroscopy.

\subsection{Modus operandi}

As a result of its popularity, lecturers present at a symposium usually request to be the hosts for the following year. With this detail decided the previous year, liaison with the representative from the tertiary institution starts in January each year to set a date for the YSS to be in September/October of that year. This information is sufficient to start advertising the event for participants and delegates to attend.

A "call for papers" notice is prepared in poster format and circulated early, around February, each year to ensure that it is planned into annual academic programs of the various chemistry, physics and geology departments. Electronic and hard copies are circulated to the SASS members and to all the tertiary institutions nationally. This informs the academics and all the industrial spectroscopists of the deadlines and other relevant details. During the course of the next four months, a reminder of the meeting is circulated electronically to all members again. Any newsletters that are issued after February include the "call for papers" notice as well. Over the last four years there have been an average of fourteen students participating each year. The main criterion is that the topic of the presentation must be about spectroscopy.

During February and March and in liaison with the hosts, practical arrangements are finalized for the symposium day; i.e. decision for which local caterer, the lecture theatre and parking area to be used, hard copy and electronic versions of maps to the venue, etc.

As soon as the individual abstracts are submitted, they are electronically circulated to all the Executive Committee Members of SASS for evaluation and comment. On an individual basis, the student and lecturer/mentor is notified of the acceptance of the paper, with any recommendations for amendment included in that communication.

A panel of five judges is selected, of which at least three are academics. The judges may not be linked in any way to the research projects and the students presenting at the symposium. Two consistent judges presiding each year, are the managing director of PANalytical, SA and the President of the SASS. PANalytical traditionally are the main sponsors for the YSS. 
To assist the adjudication and maintain a fair system, the judges are briefed in the use of a "score sheet" for each candidate. On the score sheet, $50 \%$ of the marks are allocated to the technical content of the paper delivered, $25 \%$ for format, audio-visual appearance, voice projection and confidence and the remaining $25 \%$ allocated to answering questions and adherence to the time slot on the program. An overall score is calculated for each presenter from the individual score cards recorded by the five judges. The top three candidates in the competition are awarded first, second and third prizes, which are described later under point 2.4.

The overall winner not only receives the first prize, but the Albert Strasheim floating trophy as well. The trophy is returned two weeks prior to the next YSS in the following year.

Students are prepared in advance to know what is expected on the day of the competition. In reply to acceptance of the abstract submitted, a copy of the score sheet is forwarded to each student and his/her mentor for preparation purposes. The target submission date of abstracts is one month prior to the event. From this information, a program is planned for the symposium. The format usually is to start by 08:30 and finish around 17:00, with a tea/coffee break midmorning, a 30minute lunch break at midday and one afternoon tea/coffee break. A fair amount of student social interaction takes place during the breaks. Lecturers have the opportunity to talk to their counterparts at the other institutions. Delegates have an opportunity to meet with colleagues in spectroscopy and there is a lot of goodwill and talking amongst the contenders for the prizes during the social intervals.

The day is rounded off by a forty-five minute slot, which is reserved for either a motivational or instructive talk. Examples of the instructive talks are "How to prepare a good presentation" by emeritus professor James Willis and the "Mind-mapping" by Dr Jardin, a consultant, both of whom were willing to donate their time to be at the YSS. Another interesting and motivational talk was given last year by Mr Zwannda Ramadwa, namely, " Nuturing a culture of innovation and development in technology by bringing SET (science, engineering and technology) literacy to our nation". This year a workshop was held during which students were asked to indicate what role they wanted to see the professional society playing in assisting young scientists with their development and growth in their careers.

Usually the audience is made up mainly of under-and post-graduate students and their lecturers. Many lecturers attend even if they do not have students participating in the event. Participants in the competition are BSc honors, Masters and $\mathrm{PhD}$ students, who are involved with research projects. Winners of the competition return with regularity to attend the YSS. Groups or individuals from industry and members of the SASS also attend. Students are admitted at special low fees of R20-00 to encourage as many as possible to attend.

Over the years the standard of presentation given at the YSS has increased considerably. In order to preserve the integrity of the event, a few basic rules have been developed by the Executive Committee. The set of rules are circulated at the beginning of the year along with the posters for the competition.

\subsection{Integration of all spectroscopists}

Inherent in what has evolved naturally into the current way the YSS is running, is the change that has come about in the composition of the participating tertiary institutions. Where, in the past, a special effort had to be made to get the institutions that were historically "non-white" to participate, this is no longer required. Delegates and representatives from these institutions have experienced over the last five years that they are an integral part of the whole. There is no need to call upon those lecturers to join those of longer standing and the traditionally "white" forum to attend the YSS.

The students are excellent promoters and advertise the competition amongst fellow students. The word-ofmouth advertisement has contributed greatly towards our success. Adjudication is based on performance and merit alone. In this process we have had presenters in the top level of first three positions being of any of our ethnic groups in the country and a good balance between male and female winners. A fair amount of networking is beginning to show between students in similar research projects, but living in different provinces. The winners of previous years and whom attend the YSS in the years after their successful competition, are naturally interested the achievements of those following in later years. There are signs that these winners are also naturally beginning to assume some leadership to help those developing in their wake.

\subsection{Sponsors}

In South Africa the support received from spectroscopy instruments and chemical suppliers is phenomenal. They still remain the major sponsors for financial needs that arise. As mentioned before, a large contributor to the YSS is PANalytical, SA who pay for the lunch and a substantial first prize. Examples of first prizes donated in the past are a video recorder, a mini high-fidelity sound system with CD player and tuner, etc. Another sponsor is ThermoARLabs. They sponsor an air ticket for any one of the students participating from the other provinces to go to Gauteng for the event. Each tertiary institution, which has hosted the YSS in the past six years, has sponsored the venue and coffee/tea breaks. Many of the lecturers give support to pay for the accommodation for their students 
when they have to travel from far destinations the night before the event. The SASS sponsors any other students for their traveling costs in order to be at the YSS. The SASS also sponsors the second and third prizes, book vouchers of R200-00 and R300-00 respectively.

\section{Future Plans}

It has already been mentioned that the last slot at the YSS this year was an interactive discussion with the students present on how they saw the role of the professional society in future assisting a developing spectroscopist in his/her career. A number of suggestions were noted for the SASS Executive Committee to investigate and implement where practicable. This action will take place during October 2003.

One aspect that has become evident during the period of preparation for and during the YSS is that the students are naturally gravitating towards leaders, and previous contestants are helping the upcoming spectroscopists with their presentations. A suggestion was made to the students that a representative is chosen at each tertiary institution to be the channel of communication linking from the students to the SASS and vice versa. In this way, we could dispatch our newsletters and advertisements of spectroscopy meetings taking place, to all students involved in science and spectroscopy research, regardless of whether they are members or not. The SASS would automatically form part of the networking at that level to the benefit of both parties. The appointment of a representative in the form of one of the more mature students at MSc or PhD level for spectroscopy amongst the post-graduates, would lead to graduate mentorships forming.

Rural science teachers are desperately in need of assistance, especially in previously disadvantaged communities. Spectroscopy graduates who are willing to get involved, could be included in the current outreach programs that are ongoing to address school groups about the importance of science education and the careers available to scientists. On these outreach programs, the students who spend time at the schools could help the teachers in their attempts to create parental awareness for learners who are showing the potential to follow a scientific career. In order to generate interest and motivation at school level, graduates could be encouraged to give talks in their own communities about their careers and their achievements.

Improved communications and assistance programs are instrumental in the SASS members being more informed of unemployed graduates. A natural spin-off of the improved networking in future will be added assistance for graduates seeking employment, where possible.

It is necessary to develop the wider involvement of the SASS in slow measures due to the voluntary and parttime basis on which the SASS Executive Committee operates. There are no individuals or SASS members who are able to focus on any of these activities of the society exclusively. All resources are from funds generated by arranging meetings, conferences, etc. However, it is believed that these activities that are to be developed during this next term of office will benefit the members and the field of spectroscopy. Evolving with the needs of the future generation of spectroscopists will also ensure that we keep the SASS alive and doing well in Africa.

I have included a copy each of a typical YSS program and the score sheet on the next three pages as examples of what is currently done for the YSS.

\section{Acknowledgements}

I want to thank the following organizations for their sponsorships for me to travel to the ETOP, 2003.

ICO - The International Commission for Optics

OSA - The Optical Society of America

APIE - The International Society of optical Engineers 


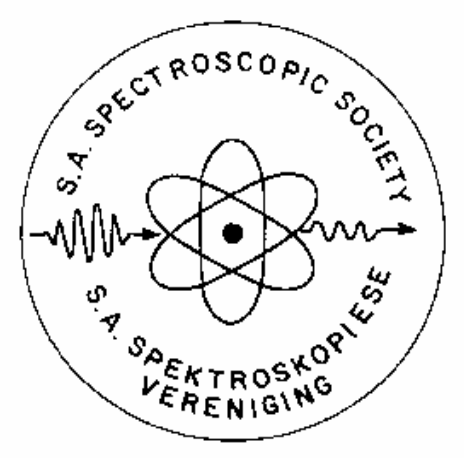

\title{
Young Spectroscopists Symposium 12 August 2003
}

\author{
Evaluation of presenters
}

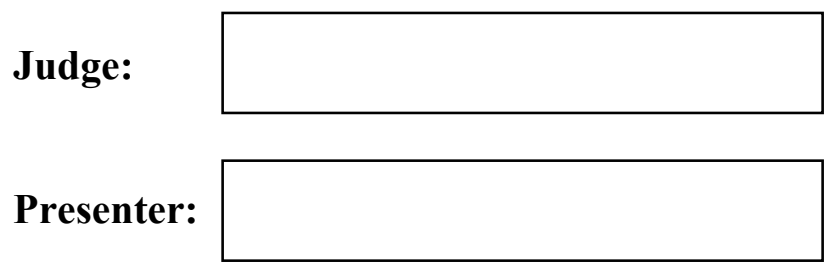

\begin{tabular}{|c|c|c|c|}
\hline & & Rating & Comments \\
\hline Content & $50 \%$ & & \\
\hline Format & \multirow{4}{*}{$25 \%$} & & \\
\hline Audio-visual appearance & & & \\
\hline Voice projection & & & \\
\hline Confidence & & & \\
\hline Answering questions & $15 \%$ & & \\
\hline Timing & $10 \%$ & & \\
\hline Total & $100 \%$ & & \\
\hline
\end{tabular}




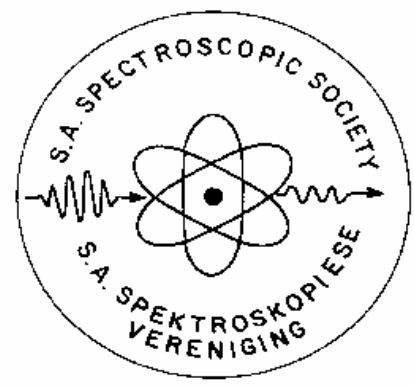

\title{
SOUTH AFRICAN SPECTROSCOPIC SOCIETY SUID-AFRIKAANSE SPEKTROSKOPIESE VERENIGING
}

\section{September 2002}

\section{Programme for Young Spectroscopist Symposium}

\author{
08:30-08:50 Registration \\ 08:50 - 09:10 Welcome - Prof Boeyens: University of Pretoria \\ Ms Janette Cawood: President SASS \\ Ms Maggi Loubser: Chairman \\ 09:10- 09:30 C. Canario, Technikon Pretoria \\ Atomic AbsorptionSpectrometric detemination of $\mathrm{Cd}, \mathrm{Pb}$ and $\mathrm{Mn}$ in urine with the Transverse \\ Heated Filter Atomiser. \\ 09:30 - 09:50 S. Mtongana, University of Stellenbosch \\ The structural elucidation of platinum(II) chelates of N-diisopropoxythiophosphoryl thioamide \\ and N-diisopropoxythiophosphoryl-N-phenylthiourea by means of multinuclear NMR \\ spectroscopy. \\ 09:50 - 10:10 A. du Plessis, University of Stellenbosch \\ A tunable pulsed Raman laser for IR spectroscopy. \\ 10:10 - 10:30 N. Mhlahlo, University of Cape Town \\ Analysis of Spectroscopic observations of the cataclysmic variable, TX Col. \\ 10:30- 10:50 S Govender, University of Cape Town \\ Lead concentration and isotopic composition by mass spectrometry and their implication for \\ anthropogenic components at farms in Philippi, W Cape - a pilot study.
}

10:50 - 11:15 TEA

11:15 - 11:35 M. Lumka, Vista University, Soweto Campus

X-Ray Fluorescence analysis of aerosols from Venda and Bethlehem.

11:35 - 11:55 J. Mnisi, Vista University, Soweto Campus

Development of a novel method for slag sampling employing XRF spectrometry.

11:55 - 12:15 S Madileng. Vista University, Soweto Campus

Species.

12:15 - 12:35 P. Swafo, University of South Africa

12:35 - 12:55 M Legodi, University of Pretoria

Raman Spectra of clays and pigments used in ancient artefacts.

\section{2:55 - 13:30 LUNCH}

13:30 - 13:50 N. Krusberski, Rand Afrikaans University

analyses.

13:50-14:10

The evaluation of different calibration strategies using emulsions for wear-metal-in-oil

S. Jansen van Vuuren, Rand Afrikaans University

The simultaneous separation and determination of $\mathrm{Cr}$ (III) and $\mathrm{Cr}(\mathrm{VI})$ species by ion chromatography - inductively coupled plasma - optical emission spectrometry. 

$14: 10-14: 30$
Z. Foldvarl, University of Pretoria
Determination of the stereoselectivity of sharpless epoxidation/kinetic resolution of (3RS)-7- [(tert-butyldimethylsilyl)oxy] -hept-1-en-3-ol by nuclear magnetic resonance spectroscopy.
$14: 30-14: 50$
A. Whaley, University of Pretoria
Selective ionisation techniques for mass spectrometry.

\section{4:50 - 15:20 TEA \\ 15:20 - 15:30 Prizegiving \\ 15:30 - 16:30 Mr Z Ramadwa,}
Nuturing a culture of innovation and development in technology by bringing SET
16:30 - 16:45 Conclusion and Acknowledgements - Ms Janette Cawood 